\title{
Diverging trends of chronic bronchitis and smoking habits between 1998 and 2010
}

Simone Accordini ${ }^{1 *}$, Angelo Guido Corsico ${ }^{2}$, Isa Cerveri ${ }^{2}$, Leonardo Antonicelli ${ }^{3}$, Francesco Attena ${ }^{4}$, Roberto Bono ${ }^{5}$, Lucio Casali ${ }^{6}$, Marcello Ferrari ${ }^{7}$, Alessandro Fois ${ }^{8}$, Pierpaolo Marchetti ${ }^{1}$, Pietro Pirina ${ }^{8}$, Roberta Tassinari ${ }^{5}$,

Giuseppe Verlato ${ }^{1}$ and Roberto de Marco ${ }^{1}$

\begin{abstract}
Background: No study has been carried out on the time trend in the prevalence of chronic bronchitis (CB) in recent years, despite its clinical and epidemiological relevance. We evaluated the trend in CB prevalence during the past decade among young Italian adults.

Methods: A screening questionnaire was mailed to general population samples of 20-44 year-old subjects in two cross-sectional surveys: the Italian Study on Asthma in Young Adults (ISAYA) (1998/2000; $n=18,873,9$ centres) and the screening stage of the Gene Environment Interactions in Respiratory Diseases (GEIRD) study (2007/2010; $n=$ $10,494,7$ centres). CB was defined as having cough and phlegm on most days for a minimum of 3 months a year and for at least 2 successive years. The prevalence rates and the risk ratios (RRs) for the association between CB and each potential predictor were adjusted for gender, age, season of response, type of contact, cumulative response rate, and centre.
\end{abstract}

Results: CB prevalence was 12.5\% (95\% Cl: $12.1-12.9 \%)$ in 1998/2000 and 12.6\% (95\% Cl: 11.7-13.7\%) in 2007/2010; it increased among never smokers (from 7.6 to $9.1 \%, p=0.003$ ), current light smokers ( $<15$ pack-years; from 15.1 to $18.6 \%, p<0.001$ ), and unemployed/retired subjects (from 14.3 to $19.1 \%, p=0.001$ ). In this decade, the prevalence of current smoking decreased (from 33.6 to 26.9\%, $p<0.001$ ), whereas the prevalence of unemployment/premature retirement (from 5.3 to $6.0 \%, p=0.005$ ), asthma (from 5.0 to $6.2 \%, p=0.003$ ), and allergic rhinitis (from 19.5 to $24.5 \%, p<0.001$ increased. In both 1998/2000 and 2007/2010, the likelihood of having CB was significantly higher for women, current smokers, asthmatic patients, and subjects with allergic rhinitis. During this period, the strength of the association between CB and current heavy smoking ( $\geq 15$ pack-years) decreased (RR: from 4.82 to 3.57, $p=$ 0.018), whereas it increased for unemployment/premature retirement (from 1.11 to 1.53, $p=0.019$ ); no change was observed for gender, asthma, and allergic rhinitis.

Conclusions: Despite the significant reduction in current smoking, CB prevalence did not vary among young Italian adults. The temporal pattern of CB prevalence can only be partly explained by the increase of unemployment/ premature retirement, asthma and allergic rhinitis, and suggests that other factors could have played a role.

Keywords: Allergic rhinitis, Asthma, Chronic bronchitis, Cigarette smoking, Epidemiology

\footnotetext{
* Correspondence: simone.accordini@univr.it

'Unit of Epidemiology and Medical Statistics, Department of Public Health and Community Medicine, University of Verona, c/o Istituti Biologici II, Strada Le Grazie 8, 37134, Verona, Italy

Full list of author information is available at the end of the article
} 


\section{Background}

Chronic bronchitis (CB) (i.e. a mucus-producing cough on most days for a minimum of 3 months a year and for at least 2 consecutive years) is a highly prevalent respiratory disorder, usually associated with cigarette smoking $[1,2]$. CB can precede the development of chronic obstructive pulmonary disease (COPD) [3,4], and it increases the likelihood of exacerbations, hospitalization, and mortality in COPD patients [5-7]. Passive smoking, air pollution, and occupational exposures to dust, gas, and fumes can also increase the risk of $\mathrm{CB}$ [8-10]. Furthermore, $\mathrm{CB}$ may be associated with asthma and may be a marker of both asthma severity [11] and poor control of symptoms [12], which in turn are associated with a heavy socio-economic burden [13-15]. CB in asthmatic subjects may also indicate the presence of the asthmaCOPD overlap syndrome, which is a difficult condition to treat [16]. In addition, $\mathrm{CB}$ can be related to allergic rhinitis and gastroesophageal reflux disease (GORD) $[17,18]$.

While the prevalence of asthma and allergic rhinitis increased during the last decade in Italy [19], so far no study has been carried out on the time trend in the prevalence of $\mathrm{CB}$ in recent years, despite its clinical and epidemiological relevance. Accordingly, the present study is aimed at evaluating the ten-year trend in the prevalence of $\mathrm{CB}$ among young adults (20-44 years) in Italy, and at evaluating whether the pattern of the association with potential predictors changed during the last decade. To fulfil these objectives, we used the data from two cross-sectional surveys, the Italian Study on Asthma in Young Adults (ISAYA) [20] and the screening stage of the Gene Environment Interactions in Respiratory Diseases (GEIRD) study [21].

\section{Methods}

Design of the study and definitions

ISAYA and GEIRD-screening stage were two crosssectional surveys on respiratory health in the general adult population, which were carried out in Italy between 1998-2000 and between 2007-2010, respectively. ISAYA involved 25,969 subjects from 9 centres (Ferrara, Pavia, Pisa, Sassari, Sassuolo, Siracusa, Turin, Udine, Verona) with an overall response rate of $72.7 \%$ [20], whereas GEIRD involved 18,357 subjects from 7 centres (Ancona, Pavia, Salerno, Sassari, Terni, Turin, Verona) with an overall response rate of $57.2 \%$ [19]. In both the studies, random samples of 3,000 subjects aged 20-44 $(\mathrm{men} /$ women ratio $=1)$ were selected in each centre from the general population, using the local health authority registers. A screening questionnaire $[21,22]$ was mailed to each subject up to three times and then administered by telephone in case of non response. Ethics approval was obtained in each centre involved in GEIRD from the appropriate ethics committee (Comitato Etico dell'Azienda Ospedaliero-Universitaria Ospedali Riuniti di Ancona; Comitato di Bioetica della Fondazione IRCCS Policlinico San Matteo di Pavia; Comitato Etico dell'Azienda Sanitaria Locale SA/2 di Salerno; Comitato di Bioetica dell'Azienda Sanitaria Locale di Sassari; Comitato Etico delle Aziende Sanitarie dell'Umbria di Perugia; Comitato Etico dell'Azienda Sanitaria Locale TO/2 di Torino; Comitato Etico per la Sperimentazione dell'Azienda Ospedaliera Istituti Ospitalieri di Verona). All participants were fully informed about all aspects of the research project and consented to complete and return the questionnaire.

The screening questionnaires used in ISAYA and GEIRD shared a set of core questions (mainly taken from the European Community Respiratory Health Survey [ECRHS] questionnaires [23]) on the presence of asthma (self-report of the disease during lifetime with or without a physician diagnosis, frequency of asthma attacks and use of anti-asthmatic drugs in the last 12 months), asthma-like symptoms (wheezing, nocturnal tightness in the chest, and attacks of shortness of breath at night time in the last 12 months), allergic rhinitis (any nasal allergies, including hay fever), and CB (cough and phlegm on most days for a minimum of 3 months a year and for at least 2 successive years), as well as questions on smoking habits (the age of smoking commencement, the amount of tobacco smoked, and the age at which smokers stopped smoking). The screening questionnaire used in GEIRD also contained questions on the frequency of vehicular traffic (cars and trucks) near home.

Smoking habits were classified as current light/heavy smoking, past light/heavy smoking, or never smoking according to lifetime pack-years, considering 15 packyears as the cut-off. Ever smoking was defined as having smoked at least one cigarette per day or one cigar a week for one year. Asthma was considered present if a subject had reported asthma confirmed by a doctor and at least one respiratory symptom (wheezing, nocturnal tightness in the chest, attacks of shortness of breath at night time) or at least one attack of asthma or use of medicines because of breathing problems in the last 12 months.

\section{Statistical analysis}

The data from all the centres that participated in ISAYA and/or GEIRD were used in the analysis. Gender, age, season of response, type of contact, and cumulative response rate were considered as potential confounders because of differences in their distribution between the two surveys (Table 1). In particular, the cumulative response percentile rank was used: each subject was ordered by study and centre according to the date of response to the questionnaire, and then he/she was 
Table 1 Distribution of the design variables

\begin{tabular}{|c|c|c|c|}
\hline & ISAYA $(1998 / 2000) N=25,969$ & GEIRD $(2007 / 2010) N=18,357$ & p-value* \\
\hline $\mathrm{N}^{\circ}$ of responders (response rate, \%) & $18,873(72.7)$ & $10,494(57.2)$ & $<0.001$ \\
\hline Season at time of the interview, $\%$ & & & $<0.001$ \\
\hline spring & 18.5 & 41.0 & \\
\hline summer & 16.4 & 22.1 & \\
\hline autumn & 40.4 & 25.7 & \\
\hline winter & 24.7 & 11.2 & \\
\hline Phone contact, \% & 27.9 & 11.8 & $<0.001$ \\
\hline Females, \% & 50.7 & 52.3 & 0.008 \\
\hline Age (years), mean (sd) & $33.1(6.9)$ & $34.7(7.1)$ & $<0.001$ \\
\hline
\end{tabular}

* $\mathrm{p}$-value obtained by Pearson's chi-squared test and two-sample t test with unequal variances.

attributed the ratio between his/her rank and the number of eligible subjects [19].

Adjusted prevalence rates of CB were computed by logistic regression models. The models had an indicator of the presence of $\mathrm{CB}$ as the dependent variable and the study (GEIRD vs ISAYA), the potential confounders reported above, and centre as covariates. Centre was included in the models in order to partly control for the potential confounding effect of ecological-level variables, such as environmental factors. Since the subjects were nested into groups (the study -ISAYA or GEIRD- in which they participated, crossed by centre), clustered sandwich estimators of the variance were used. The prevalence rates in each survey were estimated by setting the distribution of gender, season of response, type of contact, and centre equal to the average distribution, and by setting age and the cumulative response rate equal to the overall mean [24], in order to make the ISAYA and GEIRD estimates comparable.

The association between gender, smoking habits, occupational status, asthma, allergic rhinitis, and the presence of $\mathrm{CB}$ was estimated by the risk ratios (RRs), separately for each survey. The RRs were computed by Poisson regression models with robust standard errors (obtained by the Huber/White/sandwich estimator of the variance) and no offset [25], and were adjusted for the potential confounding effect of the same variables as the prevalence rates. The RRs were also computed by including a dummy variable for the high frequency of vehicular traffic (i.e. a continuous passage of cars and/or trucks) near home in the GEIRD model.

The statistical analysis was performed using STATA software, release 12 (StataCorp, College Station, TX).

\section{Results}

Ten-year trend in the prevalence of $\mathrm{CB}$

The prevalence of CB was $12.5 \%$ (95\% CI: $12.1-12.9 \%)$ in 1998/2000 and 12.6\% (95\%CI: $11.7-13.7 \%)$ ten years later, and it did not significantly vary according to gender and age (Table 2). A statistically significant trend in the prevalence of $\mathrm{CB}$ was observed among never smokers (from 7.6 to 9.1\%, $\mathrm{p}=0.003$ ) and current light smokers ( $<15$ pack-years: from 15.1 to $18.6 \%, \mathrm{p}<0.001)$, but not among current heavy smokers ( $\geq 15$ pack-years) and past smokers (Figure 1). According to occupational status, the prevalence of $\mathrm{CB}$ significantly increased among unemployed/retired subjects (from 14.3 to $19.1 \%, \mathrm{p}=$ 0.001), but not among employed subjects/house-persons/students (from 12.3 to $12.1 \%, \mathrm{p}=0.764$ ).

\section{Ten-year trend in the distribution of smoking habits,} occupational status, asthma, and allergic rhinitis

During this period, there was a statistically significant decrease in the percentage of current smokers (from 33.6 to $26.9 \%, \mathrm{p}<0.001)$ and in the percentage of current smokers according to the amount of exposure (current light smokers: from 22.5 to $19.8 \%, \mathrm{p}<0.001$; current heavy smokers: from 7.0 to $4.2 \%, \mathrm{p}<0.001$ ) (Table 3). Moreover, a statistically significant change was observed in the percentage of past heavy smokers (from 1.2 to $0.8 \%, \mathrm{p}<0.001$ ), but not in the percentage of past light smokers. In addition, a statistically significant increase was observed in the percentage of unemployed/ retired individuals (from 5.3 to $6.0 \%, \mathrm{p}=0.005$ ), asthmatic patients (from 5.0 to $6.2 \%, \mathrm{p}=0.003$ ), and subjects with allergic rhinitis (from 19.5 to $24.5 \%, \mathrm{p}<0.001$ ). In the same decade, there was no statistically significant change in the percentage of asthmatic patients who also reported $\mathrm{CB}$, and in the percentage of subjects with allergic rhinitis and coexisting CB (Table 4).

\section{Changes in the pattern of the association between the presence of $C B$ and the potential predictors}

In both 1998/2000 and 2007/2010, the likelihood of having CB was significantly higher for women, current smokers and past heavy smokers (as compared to never smokers), asthmatic patients, and subjects with allergic rhinitis (Table 5). During this ten-year period, the 
Table 2 Adjusted prevalence of CB according to gender and age

\begin{tabular}{|c|c|c|c|c|}
\hline & & \multicolumn{2}{|c|}{ Adjusted prevalence (\%) $[95 \% \mathrm{Cl}]$} & \multirow[b]{2}{*}{ p-value } \\
\hline & & ISAYA (1998/2000) & $\overline{\text { GEIRD }(2007 / 2010)}$ & \\
\hline \multirow[t]{2}{*}{ Gender* } & Males & $12.3[12.0-12.6]$ & $12.6[11.8-13.4]$ & 0.575 \\
\hline & Females & $12.6[11.9-13.3]$ & $12.7[11.3-14.3]$ & 0.920 \\
\hline \multirow[t]{2}{*}{$\mathrm{Age}^{+}$} & $<30$ years & $11.8[11.2-12.5]$ & $12.2[10.9-13.6]$ & 0.577 \\
\hline & $\geq 30$ years & $12.7[12.2-13.2]$ & $12.9[12.0-13.8]$ & 0.692 \\
\hline TOTAL" & & $12.5[12.1-12.9]$ & $12.6[11.7-13.7]$ & 0.781 \\
\hline
\end{tabular}

* prevalence obtained by stratifying on gender and adjusted for age, season of response, type of contact, cumulative response rate, and centre.

+ prevalence obtained by stratifying on age and adjusted for gender, season of response, type of contact, cumulative response rate, and centre.

^ prevalence adjusted for gender, age, season of response, type of contact, cumulative response rate, and centre.

₹ $p$-value obtained by testing the null hypothesis that the regression coefficient of the dummy indicator of the study (GEIRD vs ISAYA) was zero.

strength of the association between smoking habits and the presence of $\mathrm{CB}$ decreased (with a dissimilar change in the RRs according to pack-years for both past and current smoking), whereas the strength of the association increased for unemployment/premature retirement. No change in the RRs was observed for gender, asthma, and allergic rhinitis. When the high frequency of vehicular traffic near home was also considered in the GEIRD model (2007/2010), traffic-related air pollution was significantly associated with the presence of CB (RR $=1.27$; 95\% CI: $1.14-1.41$ ).

\section{Sensitivity analysis}

These results were confirmed when only the data from the four centres (Pavia, Sassari, Turin, Verona) that had participated in both the surveys were considered in the analysis. In particular, the prevalence of CB was $12.4 \%$ in $1998 / 2000$ and $12.5 \%$ in $2007 / 2010$, and the estimates of the RRs were comparable to those obtained in the main analysis (an additional table shows this in more detail [see Additional file 1]).

\section{Discussion}

The main results of the present study are the following:

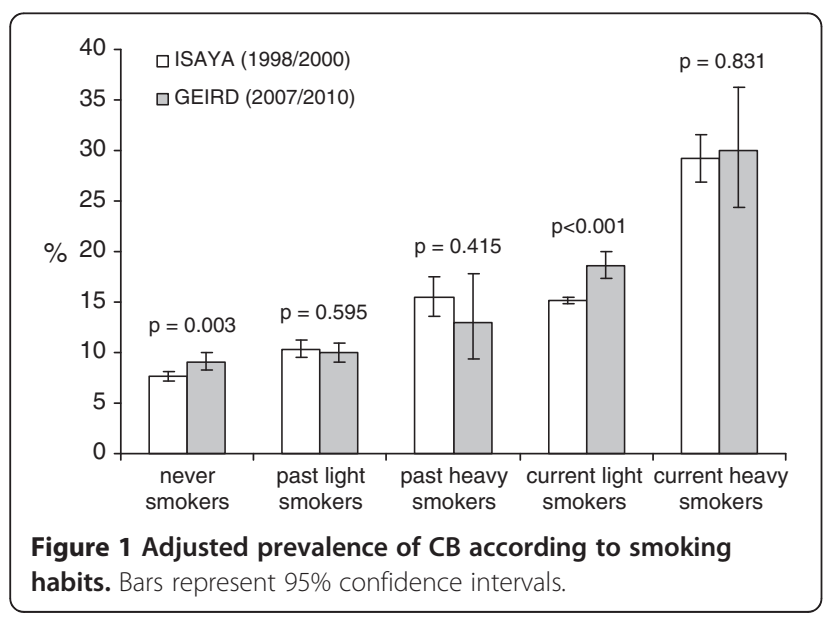

- the prevalence of $\mathrm{CB}$ did not vary during the past decade among young adults in Italy, despite a 7\% reduction in the percentage of current smokers; - the increase in the prevalence of $\mathrm{CB}$ among never smokers and the decrease in the strength of the association between current smoking and $\mathrm{CB}$ observed in the last ten years, suggest that factors other than smoking could have played a major role in determining the trend in the prevalence of $\mathrm{CB}$;

- $\mathrm{CB}$ is common in asthmatic patients and in subjects with allergic rhinitis, and its association with these respiratory diseases has not changed with time.

The prevalence of $C B$ did not change in the past decade, despite the striking reduction in the percentage of current smokers

The prevalence rates of $\mathrm{CB}$ among 20-44 year-old subjects remained stable during the past ten years in Italy and were similar to that reported in the three Italian centres (Pavia, Turin, Verona) that had participated in the ECRHS in 1991/1993 (median prevalence: 11.3\%) [17]. Moreover, the estimates from ISAYA and GEIRD are comparable to that obtained for the same age class in 16 industrialized countries in the ECRHS (10.2\%) [17]. The impressive prevalence rates of $\mathrm{CB}$ estimated from the ISAYA and GEIRD studies enlighten the fact that $\mathrm{CB}$ is a substantial health problem even in young adults. Although CB may not lead to COPD in many of these subjects, our estimates suggest that the base of the COPD iceberg was wide and did not decrease during the past decade in Italy [2].

It could be surprising that there was no significant decrease in the prevalence of $\mathrm{CB}$ during the past decades in view of the fact that the percentage of current smokers decreased in Italy during the last twenty years [26], as also documented in our study. In fact, the relationship between smoking and CB is well known, and the amount of tobacco smoke determines the frequency and severity of symptoms [2,27]. Accordingly, we found that smoking habits is the strongest predictor of the presence of $\mathrm{CB}$, since the RRs were the highest for current smoking. In 
Table 3 Adjusted percentage* of past/current smokers, unemployed/retired subjects, subjects with asthma, and subjects with allergic rhinitis

\begin{tabular}{|c|c|c|c|}
\hline & \multicolumn{2}{|c|}{ Adjusted \% [95\% Cl] } & \multirow[b]{2}{*}{ p-value } \\
\hline & ISAYA (1998/2000) & GEIRD $(2007 / 2010)$ & \\
\hline Past light smokers & $11.2[10.9-11.6]$ & $11.7[11.1-12.2]$ & 0.219 \\
\hline Past heavy smokers & $1.2[1.1-1.3]$ & $0.8[0.7-1.0]$ & $<0.001$ \\
\hline Current light smokers & $22.5[22.0-23.1]$ & $19.8[18.9-20.7]$ & $<0.001$ \\
\hline Current heavy smokers & $7.0[6.7-7.4]$ & $4.2[3.8-4.6]$ & $<0.001$ \\
\hline Unemployed/retired subjects & $5.3[5.1-5.6]$ & $6.0[5.7-6.3]$ & 0.005 \\
\hline Subjects with asthma & $5.0[4.7-5.3]$ & $6.2[5.6-6.8]$ & 0.003 \\
\hline Subjects with allergic rhinitis & $19.5[19.2-19.9]$ & $24.5[23.8-25.2]$ & $<0.001$ \\
\hline
\end{tabular}

* adjusted for gender, age, season of response, type of contact, cumulative response rate, and centre.

${ }^{+} \mathrm{p}$-value obtained by testing the null hypothesis that the regression coefficient of the dummy indicator of the study (GEIRD vs ISAYA) was zero.

addition, the strength of the association increased according to the amount of past and current active exposure. However, the prevalence of $\mathrm{CB}$ significantly increased among never smokers during the past decade, resulting in a reduction of the strength of the association between $\mathrm{CB}$ and smoking. Hence, our findings add to the emerging evidence that factors other than smoking play a major role in respiratory diseases [28].

\section{Temporal variation in the association between the presence of $C B$ and other factors}

The risk of having CB among unemployed/retired subjects significantly increased during the past decade. Unemployment/premature retirement can be considered a proxy measure for socio-economic status. Socioeconomically disadvantaged subjects might be more susceptible to respiratory infections, such as pertussis, repeated viral infections, and tuberculosis. Moreover, the observed association could be due to factors, such as residential and workplace pollutant exposures [29], which affect respiratory health and which are more frequent in lower social classes, or could reflect a cumulative life course disadvantage [30]. The high prevalence of CB among unemployed/retired subjects in 2007/2010 supports the need for public health programs focused on vulnerable populations. In fact, the relationship between good health and sustaining employment strengthened during the last decades due to decreasing employment rates and increasing economic inactivity rates among subjects with poor health [31].

The strength of the association between the presence of $\mathrm{CB}$ and gender has not significantly changed during the past decade in Italy, and females showed a higher risk of having $\mathrm{CB}$ as compared to males, regardless of their smoking habits and socio-economic status, and the coexistence of asthma and allergic rhinitis. A possible explanation is that females may have more sensitive cough receptors than males [32]. Moreover, sex hormones may have an effect on airway reactivity [33].

The time trend in the prevalence of $\mathrm{CB}$ could have been influenced by factors other than smoking habits or socio-economic status, which were not measured in the present study. In fact, many causes may account for $\mathrm{CB}$, especially in never smokers. In particular, we were not able to investigate the association with: i) passive smoking exposure, which is still common and it has been found to be significantly related to all types of respiratory symptoms [34]; ii) occupational exposures to dust, gas, and fumes over a long period of time, which has been documented to be a cause of CB [10]; iii) GORD $[17,18]$, which is due to the fact that the acid reflux consumes the airways or the bronchi and triggers the body to create increased levels of mucus.

Finally, the exposure to outdoor air pollution was only investigated in 2007/2010 using a proxy variable of traffic-related air pollution near home. However, the

Table 4 Adjusted prevalence of CB according to the presence of asthma and allergic rhinitis

\begin{tabular}{lcccc}
\hline & & \multicolumn{2}{c}{ Adjusted prevalence (\%) [95\% Cl] } & \\
\cline { 3 - 4 } & & ISAYA (1998/2000) & GEIRD (2007/2010) & p-value \\
\hline Asthma* & Absent & $11.0[10.5-11.5]$ & $3.7[9.7-11.8]$ & 0.665 \\
& Present & $31.2[29.9-32.5]$ & $33.3[31.5-35.1]$ & 0.144 \\
Allergic rhinitis* & Absent & $10.5[10.2-10.9]$ & $9.7[8.8-10.6]$ & 0.124 \\
& Present & $19.9[19.0-20.8]$ & $21.2[20.0-22.5]$ & 0.163 \\
\hline
\end{tabular}

* prevalence obtained by stratifying on asthma/allergic rhinitis and adjusted for gender, age, season of response, type of contact, cumulative response rate, and centre.

${ }^{+} \mathrm{p}$-value obtained by testing the null hypothesis that the regression coefficient of the dummy indicator of the study (GEIRD vs ISAYA) was zero. 
Table 5 Mutually adjusted risk ratios (RRs)* for the association between CB and each potential predictor

\begin{tabular}{|c|c|c|c|}
\hline & \multicolumn{2}{|c|}{ RR $[95 \% \mathrm{Cl}]$} & \multirow[b]{2}{*}{$\begin{array}{c}\text { p-value for } \\
\text { heterogeneity }\end{array}$} \\
\hline & $\begin{array}{c}\text { ISAYA } \\
(1998 / 2000) \\
\end{array}$ & $\begin{array}{c}\text { GEIRD } \\
(2007 / 2010) \\
\end{array}$ & \\
\hline Gender (female vs male) & $1.17[1.09-1.27]$ & $1.11[1.00-1.22]$ & 0.721 \\
\hline \multicolumn{4}{|l|}{ Smoking habits (vs never smoking): } \\
\hline Past light smoking & $1.40[1.21-1.62]$ & $1.03[0.86-1.23]$ & 0.015 \\
\hline Past heavy smoking & $2.47[1.96-3.13]$ & $1.66[1.19-2.31]$ & 0.151 \\
\hline Current light smoking & $2.15[1.95-2.37]$ & $1.95[1.73-2.19]$ & 0.144 \\
\hline Current heavy smoking & $4.82[4.31-5.39]$ & $3.57[3.11-4.11]$ & 0.018 \\
\hline $\begin{array}{l}\text { Occupational status (unemployed/retired subject vs } \\
\text { employed subject/house-person/student) }\end{array}$ & $1.11[0.97-1.28]$ & $1.53[1.31-1.79]$ & 0.019 \\
\hline Asthma (present vs absent) & $2.08[1.84-2.34]$ & $2.01[1.77-2.30]$ & 0.635 \\
\hline Allergic rhinitis (present vs absent) & $1.76[1.60-1.93]$ & $1.81[1.63-2.02]$ & 0.680 \\
\hline
\end{tabular}

* RRs also adjusted for age, season of response, type of contact, cumulative response rate, and centre.

${ }^{+} p$-value obtained by considering the data from both the studies in the model and by testing the null hypothesis that the regression coefficient of the interaction term between the covariate and the dummy indicator of the study (GEIRD vs ISAYA) was zero.

observed association between vehicular traffic and the presence of CB supports the evidence that long-term exposure to air pollution is causally associated with respiratory illness $[35,36]$. In particular, living close to traffic has been documented to be associated with the prevalence of $\mathrm{CB}$, which indicates that traffic-related air pollution has long-term effects on chronic respiratory disease $[9,37]$. Thus, in addition to the relatively rare episodes of incidental, heavy air pollution, the common levels of exposure to air pollutants may increase the prevalence of $\mathrm{CB}$ and other respiratory diseases.

\section{$\mathrm{CB}$, asthma, and allergic rhinitis}

The prevalence of asthma and allergic rhinitis increased in the last ten years in Italy, as already reported in a previous analysis of the ISAYA and GEIRD data [19]. Proposed contributing factors to the increase in the prevalence of asthma are the exposure to air pollution, infections, microbial substances in the environment, and obesity [38], whereas the upward trend in the prevalence of allergic rhinitis could be due to increasing air pollution, indoor environmental factors, improved hygiene practices, geo-climatic factors, or all of the above [19].

Despite the positive trend in their prevalence, the strength of the association with the presence of CB did not change for both asthma and allergic rhinitis, and our estimates are comparable to the results obtained in 16 industrialized countries in the ECRHS [17]. As already reported, the association between asthma and CB identifies a subgroup of patients characterized by frequent exacerbations, inadequate treatment, or poor disease control $[11,12]$, which result in a heavy socio-economic burden [13-15]. Alternatively, it may be a result of the coexistence of asthma with COPD [16].
In agreement with previous studies [17,39], CB was highly prevalent among subjects with allergic rhinitis. This association confirms that post-nasal drip is a frequent cause of cough, which could also contribute to the volume of sputum expectoration. In particular, allergic rhinitis is a risk factor for sinusitis [40], which is highly prevalent in the general Italian population [41] and is a cause of post-nasal drip. However, especially in this case, $\mathrm{CB}$ may be multifactorial because many patients with asthma have rhinitis and, in turn, many patients with rhinitis have asthma or are at risk of asthma $[42,43]$.

\section{Strengths and weaknesses of the study}

The temporal change in CB is likely to reflect the trend in the prevalence rather than differences in the study design or changes in health care practice. In fact, our results were obtained by analyzing the data from two large surveys, which were carried out in the general population by using the same design, sampling frame, and protocol. Moreover, our estimates are based on selfreported symptoms, which were collected throughout international validated questionnaires [23] and are less influenced by diagnostic procedures.

A few caveats should be taken into account when interpreting our results. The Italian centres participating in ISAYA or GEIRD were not chosen randomly, but on the availability of research teams that were able to carry out the survey, and only a sub-sample of the Italian centres (Pavia, Sassari, Turin, Verona) was involved in both the surveys. However, despite this non-random selection, the study centres are located all over Italy and are representative of the geographical and climatic features of the country. Moreover, the sensitivity analysis carried out by considering only these four centres gave the same results as that obtained in the main analysis. 
The participation rate declined from $72.7 \%$ in 1998/ 2000 to $57.2 \%$ in $2007 / 2010$, as observed in other epidemiological studies over the past decades [44], and this decrease may have biased our estimates. In fact, symptom prevalence may be overestimated in GEIRD if the willingness to respond to the questionnaire is related to respiratory health [45]. However, it has been suggested that declines in participation rates are not likely to have a substantial influence on the exposure-disease associations or on the point estimates of measures of interest [44].

\section{Conclusions}

Despite the significant reduction in current smoking, the prevalence of $\mathrm{CB}$ did not vary during the past decade among young adults in Italy. The temporal pattern in the prevalence of $\mathrm{CB}$ can only be partly explained by the increase in the prevalence of unemployment/premature retirement, asthma, and allergic rhinitis in the same period, and suggests that other factors could have played a role.

\section{Additional file}

Additional file 1: Table E1. Mutually adjusted RRs for the association between CB and each potential predictor. The RRs were obtained by considering only the data from the four centres (Pavia, Sassari, Turin, Verona) that had participated in both the surveys.

\section{Abbreviations}

CB: Chronic bronchitis; COPD: Chronic obstructive pulmonary disease; GORD: Gastroesophageal reflux disease; ISAYA: Italian study on asthma in young adults; GEIRD: Gene environment interactions in respiratory diseases; ECRHS: European community respiratory health survey; RR: Risk ratio; 95\% Cl: $95 \%$ confidence interval.

\section{Competing interests}

RdM, AGC, LC, MF, and PP have received a grant for the clinical stage of the GEIRD study from Chiesi Pharmaceuticals. LC has received a reimbursement for attending a symposium from Sigma-Tau Pharmaceuticals and a fee for organising education from Chiesi Pharmaceuticals. All remaining authors declare that they have no competing interests.

\section{Authors' contributions}

SA and RdM designed the study. SA, RdM, and AGC prepared the draft of the manuscript. SA did the statistical analysis. All the authors collected the data in their own centre and contributed to the interpretation of results and to the revision of the manuscript. All the authors read and approved the final manuscript.

\section{Acknowledgements}

The members of the GEIRD study group are as follows: R. de Marco, G. Verlato, M.E. Zanolin, S. Accordini, O. Bortolami, M. Braggion, V. Cappa, L. Cazzoletti, P. Girardi, F. Locatelli, A. Marcon, E. Montoli, M. Rava, R. Vesentini (Unit of Epidemiology and Medical Statistics, University of Verona, Verona, Italy); M. Ferrari, L. Donatelli, C. Posenato, V. Lo Cascio (Section of Internal Medicine, University of Verona); L. Perbellini, M. Olivieri, J. D'Amato, E. Donatini, M. Martinelli (Unit of Occupational Medicine, Azienda Ospedaliera "Istituti Ospitalieri di Verona", Verona); P.F. Pignatti, C. Bombieri, G. Malerba, A. Baldan, F. Belpinati, A.R. Lo Presti (Unit of Biology and Genetics, University of Verona); A. Poli, M. Nicolis, S. Sembeni (Unit of Hygiene and Preventive, Environmental and Occupational Medicine, University of Verona); L. Antonicelli, F. Bonifazi (Dept of Internal Medicine, Immuno-Allergic and Respiratory Diseases, Ospedali Riuniti di Ancona, Ancona); F. Attena, V. Galdo
(Dept of Public, Clinical and Preventive Medicine, II University of Naples, Naples); V. Bellia, S. Battaglia (Dept of Medicine, Pneumology, Physiology and Human Nutrition, University of Palermo, Palermo); I. Cerveri, A.G. Corsico, F. Albicini, A. Grosso (Division of Respiratory Diseases, IRCCS Policlinico "San Matteo", University of Pavia, Pavia), A. Marinoni, S. Villani, V. Ferretti (Dept of Health Sciences, University of Pavia); L. Casali, A. Miniucchi (Dept of Internal Medicine, Section of Respiratory Diseases, University of Perugia, Perugia); L. Briziarelli, M. Marcarelli (Dept of Medical-Surgical Specialties and Public Health, University of Perugia); M.G. Panico (National Health Service, Epidemiology Unit, ASL 2, Salerno); P. Pirina, A.G. Fois, F. Becciu, A. Deledda, V. Spada (Institute of Respiratory Diseases, University of Sassari, Sassari); M. Bugiani, A. Carosso, P. Piccioni, G. Castiglioni (National Health Service, CPAASL TO2, Unit of Respiratory Medicine and Allergology, Turin); R. Bono, R. Tassinari, V. Romanazzi (Dept of Public Health and Microbiology, University of Turin, Turin); G. Rolla, E. Heffler (Dept of Biomedical Sciences and Human Oncology, University of Turin); E. Migliore (Centre of Oncologic Prevention, Turin).

The screening stage of the GEIRD study was funded by the Cariverona Foundation (Verona, Italy) and by the Italian Ministry of Education, Universities and Research (MIUR). The funders had no role in design; in the collection, analysis, and interpretation of data; in the writing of the manuscript; and in the decision to submit the manuscript for publication.

\section{Author details}

${ }^{1}$ Unit of Epidemiology and Medical Statistics, Department of Public Health and Community Medicine, University of Verona, c/o Istituti Biologici II, Strada Le Grazie 8, 37134, Verona, Italy. ²Division of Respiratory Diseases, IRCCS "San Matteo" Hospital Foundation, University of Pavia, Pavia, Italy. ${ }^{3}$ Allergy Unit, Department of Internal Medicine, Immuno-Allergic and Respiratory Diseases, Ospedali Riuniti di Ancona, Ancona, Italy. ${ }^{4}$ Department of Experimental Medicine, Seconda Università di Napoli, Napoli, Italy. ${ }^{5}$ Department of Public Health and Microbiology, University of Turin, Turin, Italy. ${ }^{6}$ Chair of Respiratory Diseases, University of Perugia, Perugia, Italy. ${ }^{7}$ Section of Internal Medicine, University of Verona, Verona, Italy. ${ }^{8}$ Institute of Respiratory Diseases, University of Sassari, Sassari, Italy.

Received: 12 October 2012 Accepted: 31 January 2013

Published: 8 February 2013

\section{References}

1. Cerveri I, Accordini S, Verlato G, Corsico A, Zoia MC, Casali L, Burney P, de Marco R: Variations in the prevalence across countries of chronic bronchitis and smoking habits in young adults. Eur Respir J 2001, 18:85-92.

2. Cerveri I, Accordini S, Corsico A, Zoia MC, Carrozzi L, Cazzoletti L, Beccaria M, Marinoni A, Viegi G, de Marco R: Chronic cough and phlegm in young adults. Eur Respir J 2003, 22:413-417.

3. Lindberg A, Jonsson AC, Rönmark E, Lundgren $R$, Larsson LG, Lundbäck B: Ten-year cumulative incidence of COPD and risk factors for incident disease in a symptomatic cohort. Chest 2005, 127:1544-1552.

4. de Marco R, Accordini S, Cerveri I, Corsico A, Antó JM, Künzli N, Janson C, Sunyer J, Jarvis D, Chinn S, Vermeire $P$, Svanes $C$, Ackermann-Liebrich $U$, Gislason T, Heinrich J, Leynaert B, Neukirch F, Schouten JP, Wjst M, Burney P: Incidence of chronic obstructive pulmonary disease in a cohort of young adults according to the presence of chronic cough and phlegm. Am J Respir Crit Care Med 2007, 175:32-39.

5. Burgel PR, Nesme-Meyer P, Chanez P, Caillaud D, Carré P, Perez T, Roche N: Cough and sputum production are associated with frequent exacerbations and hospitalizations in COPD subjects. Chest 2009, 135:975-982.

6. Miravitlles M: Cough and sputum production as risk factors for poor outcomes in patients with COPD. Respir Med 2011, 105:1118-1128.

7. Guerra S, Sherrill DL, Venker C, Ceccato CM, Halonen M, Martinez FD: Chronic bronchitis before age 50 years predicts incident airflow limitation and mortality risk. Thorax 2009, 64:894-900.

8. Radon K, Büsching K, Heinrich J, Wichmann HE, Jörres RA, Magnussen H, Nowak D: Passive smoking exposure: a risk factor for chronic bronchitis and asthma in adults? Chest 2002, 122:1086-1090.

9. Sunyer J, Jarvis D, Gotschi T, Garcia-Esteban R, Jacquemin B, Aguilera I, Ackerman U, de Marco R, Forsberg B, Gislason T, Heinrich J, Norbäck D, Villani S, Künzli N: Chronic bronchitis and urban air pollution in an international study. Occup Environ Med 2006, 63:836-843. 
10. Sunyer J, Zock JP, Kromhout H, Garcia-Esteban R, Radon K, Jarvis D, Toren K, Künzli N, Norbäck D, d'Errico A, Urrutia I, Payo F, Olivieri M, Villani S, Van Sprundel M, Antó JM, Kogevinas M: Lung function decline, chronic bronchitis, and occupational exposures in young adults. Am J Respir Crit Care Med 2005, 172:1139-1145.

11. de Marco R, Marcon A, Jarvis D, Accordini S, Almar E, Bugiani M, Carolei A, Cazzoletti L, Corsico A, Gislason D, Gulsvik A, Jõgi R, Marinoni A, MartínezMoratalla J, Pin I, Janson C: Prognostic factors of asthma severity: a 9-year international prospective cohort study. J Allergy Clin Immunol 2006, 117:1249-1256.

12. Cazzoletti L, Marcon A, Janson C, Corsico A, Jarvis D, Pin I, Accordini S, Almar E, Bugiani M, Carolei A, Cerveri I, Duran-Tauleria E, Gislason D, Gulsvik A, Jõgi R, Marinoni A, Martínez-Moratalla J, Vermeire P, de Marco R: Asthma control in Europe: a real-world evaluation based on an international population-based study. J Allergy Clin Immunol 2007, 120:1360-1367.

13. Accordini S, Bugiani M, Arossa W, Gerzeli S, Marinoni A, Olivieri M, Pirina P, Carrozzi L, Dallari R, De Togni A, de Marco R: Poor control increases the economic cost of asthma. A multicentre population-based study. Int Arch Allergy Immunol 2006, 141:189-198.

14. Accordini S, Corsico A, Cerveri I, Gislason D, Gulsvik A, Janson C, Jarvis D, Marcon A, Pin I, Vermeire P, Almar E, Bugiani M, Cazzoletti L, Duran-Tauleria E, Jõgi R, Marinoni A, Martínez-Moratalla J, Leynaert B, de Marco R: The socio-economic burden of asthma is substantial in Europe. Allergy 2008, 63:116-124

15. Accordini S, Corsico AG, Braggion M, Gerbase MW, Gislason D, Gulsvik A, Heinrich J, Janson C, Jarvis D, Jõgi R, Pin I, Schoefer Y, Bugiani M, Cazzoletti L, Cerveri I, Marcon A, de Marco R: The cost of persistent asthma in Europe: an international population-based study in adults. Int Arch Allergy Immunol 2013, 160:93-101

16. Zeki AA, Schivo M, Chan A, Albertson TE, Louie S: The asthma-COPD overlap syndrome: a common clinical problem in the elderly. J Allergy 2011, 2011:861926.

17. Janson C, Chinn S, Jarvis D, Burney P: Determinants of cough in young adults participating in the European Community Respiratory Health Survey. Eur Respir J 2001, 18:647-654.

18. Gaude SG: Pulmonary manifestations of gastroesophageal reflux disease. Ann Thorac Med 2009, 4:115-123.

19. de Marco R, Cappa V, Accordini S, Rava M, Antonicelli L, Bortolami O, Braggion M, Bugiani M, Casali L, Cazzoletti L, Cerveri I, Fois AG, Girardi P, Locatelli F, Marcon A, Marinoni A, Panico MG, Pirina P, Villani S, Zanolin ME, Verlato G: Trends in the prevalence of asthma and allergic rhinitis in Italy between 1991 and 2010. Eur Respir J 2012, 39:883-892.

20. de Marco R, Poli A, Ferrari M, Accordini S, Giammanco G, Bugiani M, Villani S, Ponzio M, Bono R, Carrozzi L, Cavallini R, Cazzoletti L, Dallari R, Ginesu F, Lauriola P, Mandrioli P, Perfetti L, Pignato S, Pirina P, Struzzo P: The impact of climate and traffic-related $\mathrm{NO}_{2}$ on the prevalence of asthma and allergic rhinitis in Italy. Clin Exp Allergy 2002, 32:1405-1412.

21. de Marco R, Accordini S, Antonicelli L, Bellia V, Bettin MD, Bombieri C, Bonifazi F, Bugiani M, Carosso A, Casali L, Cazzoletti L, Cerveri I, Corsico AG, Ferrari M, Fois AG, Lo Cascio V, Marcon A, Marinoni A, Olivieri M, Perbellini L, Pignatti P, Pirina P, Poli A, Rolla G, Trabetti E, Verlato G, Villani S, Zanolin ME: The Gene-Environment Interactions in Respiratory Diseases (GEIRD) Project. Int Arch Allergy Immunol 2010, 152:255-263.

22. de Marco R, Zanolin ME, Accordini S, Signorelli D, Marinoni A, Bugiani M, Lo Cascio V, Woods R, Burney P: A new questionnaire for the repeat of the first stage of the European Community Respiratory Health Survey: a pilot study. Eur Respir J 1999, 14:1044-1048.

23. Burney PGJ, Luczynska C, Chinn S, Jarvis D: The European Community Respiratory Health Survey. Eur Respir J 1994, 7:954-960.

24. Hosmer DW Jr, Lemeshow S: Applied logistic regression. New York: John Wiley \& Sons; 1989

25. Zou G: A modified Poisson regression approach to prospective studies with binary data. Am J Epidemiol 2004, 159:702-706.

26. Ministero della salute: Attività per la prevenzione del tabagismo. Rapporto 2009. http://www.salute.gov.it.

27. Lebowitz MD, Burrows B: Quantitative relationships between cigarette smoking and chronic productive cough. Int J Epidemiol 1977, 6:107-113.

28. Salvi SS, Barnes PJ: Chronic obstructive pulmonary disease in nonsmokers. Lancet 2009, 374:733-743.

29. Wheeler BW, Ben-Shlomo Y: Environmental equity, air quality, socioeconomic status, and respiratory health: a linkage analysis of routine data from the Health Survey for England. J Epidemiol Community Health 2005, 59:948-954.

30. Ben-Shlomo Y, Kuh D: A life course approach to chronic disease epidemiology: conceptual models, empirical challenges and interdisciplinary perspectives. Int J Epidemio/ 2002, 31:285-293.

31. Minton JW, Pickett KE, Dorling D: Health, employment, and economic change, 1973-2009: repeated cross sectional study. BMJ 2012, 344:e2316.

32. Fujimura M, Kasahara K, Kamio $Y$, Naruse M, Hashimoto T, Matsuda T: Female gender as a determinant of cough threshold to inhaled capsaicin. Eur Respir J 1996, 9:1624-1626.

33. Tan KS, McFarlane LC, Lipworth BJ: Modulation of airway reactivity and peak flow variability in asthmatics receiving the oral contraceptive pill. Am J Respir Crit Care Med 1997, 155:1273-1277.

34. Janson C, Chinn S, Jarvis D, Zock JP, Torén K, Burney P: Effect of passive smoking on respiratory symptoms, bronchial responsiveness, lung function, and total serum IgE in the European Community Respiratory Health Survey: a cross-sectional study. Lancet 2001, 358:2103-2109.

35. Zemp E, Elsasser S, Schindler C, Künzli N, Perruchoud AP, Domenighetti G, Medici T, Ackermann-Liebrich U, Leuenberger P, Monn C, Bolognini G, Bongard JP, Brändli O, Karrer W, Keller R, Schöni MH, Tschopp JM, Villiger B, Zellweger JP: Long-term ambient air pollution and respiratory symptoms in adults (SAPALDIA study). The SAPALDIA Team. Am J Respir Crit Care Med 1999, 159:1257-1266.

36. Hoek G, Pattenden S, Willers S, Antova T, Fabianova E, Braun-Fahrländer C, Forastiere F, Gehring U, Luttmann-Gibson H, Grize L, Heinrich J, Houthuijs D, Janssen N, Katsnelson B, Kosheleva A, Moshammer H, Neuberger M, Privalova L, Rudnai P, Speizer F, Slachtova H, Tomaskova H, Zlotkowska R, Fletcher T: PM10, and children's respiratory symptoms and lung function in the PATY study. Eur Respir J 2012, 40:538-547.

37. Lindgren A, Stroh E, Montnémery P, Nihlén U, Jakobsson K, Axmon A: Traffic-related air pollution associated with prevalence of asthma and COPD/chronic bronchitis. A cross-sectional study in Southern Sweden Int J Health Geogr 2009, 8:2.

38. Eder W, Ege MJ, von Mutius E: The asthma epidemic. N Engl J Med 2006, 355:2226-2235

39. Montnémery P, Svensson C, Ädelroth E, Löfdahl CG, Andersson M, Greiff L, Persson CGA: Prevalence of nasal symptoms and their relation to selfreported asthma and chronic bronchitis/emphysema. Eur Respir J 2001, 17:596-603

40. Dixon AE, Kaminsky DA, Holbrook JT, Wise RA, Shade DM, Irvin CG: Allergic rhinitis and sinusitis in asthma: differential effects on symptoms and pulmonary function. Chest 2006, 130:429-435.

41. Cazzola M, Calzetta L, Bettoncelli G, Novelli L, Cricelli C, Rogliani P: Asthma and comorbid medical illness. Eur Respir J 2011, 38:42-49.

42. Bugiani M, Carosso A, Migliore E, Piccioni P, Corsico A, Olivieri M, Ferrari M, Pirina $P$, de Marco R: Allergic rhinitis and asthma comorbidity in a survey of young adults in Italy. Allergy 2005, 60:165-170.

43. Shaaban R, Zureik M, Soussan D, Neukirch C, Heinrich J, Sunyer J, Wjst M, Cerveri I, Pin I, Bousquet J, Jarvis D, Burney PG, Neukirch F, Leynaert B: Rhinitis and onset of asthma: a longitudinal population-based study. Lancet 2008, 372:1049-1057.

44. Galea S, Tracy M: Participation rates in epidemiologic studies. Ann Epidemiol 2007, 17:643-653.

45. de Marco R, Verlato G, Zanolin E, Bugiani M, Drane JW: Nonresponse bias in EC Respiratory Health Survey in Italy. Eur Respir J 1994, 7:2139-2145.

doi:10.1186/1465-9921-14-16

Cite this article as: Accordini et al:: Diverging trends of chronic bronchitis and smoking habits between 1998 and 2010. Respiratory Research 2013 14:16. 